\title{
On the generalizability of shock-elicited aggressive behavior in rats
}

\author{
ROBERT J. SBORDONE and JOHN GARCIA \\ Neuropsychiatric Institute, Center for the Health Sciences \\ University of California, Los Angeles, California 90024
}

\begin{abstract}
The aggressive behavior of rats was observed both in a colony situation and in a shockelicited aggression situation. Several aggressive behaviors seen in the colony were not observed during footshock. Shoving and upright boxing were observed in both situations, although several components of these behaviors were missing during footshock. These data suggest that behavior elicited by footshock may be "displacement" activity rather than aggressive or defensive behavior.
\end{abstract}

The shock-elicited aggression or reflexive fighting model has become the most frequently used paradigm for investigating aggressive behavior in animals (Blanchard \& Blanchard, 1977). This paradigm consists of delivering brief electric footshock to a pair of rats (Ulrich \& Azrin, 1962). When presented with this stimulus, both rats will usually assume an upright posture that consists of standing on their hind feet and facing each other with their heads tilted upward and their mouths slightly open. In this posture, they frequently strike each other with their forepaws (Miczek, 1974). While the behavior of rats in this situation has been precisely quantified and easily replicated (Powell, Frances, Braman, \& Schneiderman, 1969; Ulrich, 1966), it is not clear to what degree the aggressive behavior produced by electric shock is similar to naturally occurring aggressive behavior. Some investigators (Blanchard \& Blanchard, 1977; Blanchard, Blanchard, \& Takahashi, 1977; Moyer, 1976; Powell, Note 1) have argued that the behavioral responses elicited by footshock are primarily "defensive" and "submissive" reactions, in that they resemble the behavior of a strange rat placed into an established rat colony. Since the vast differences in housing and social history between intruder and dominant colony rats were not controlled in these studies, there are problems with this interpretation. In addition, colonies usually contain rats of both sexes. Since females are never present when two males are tested with footshock, it is not known to what degree the presence of females

The authors gratefully acknowledge the advice of Jaime Diaz, Michael T. McGuire, and James E. Spar in the preparation of this manuscript. This work was supported by Biomedical Research Support Grant USPHS RR05756-03 and NIMH Postdoctoral Training Grant MH 14646 to Robert J. Sbordone. Requests for reprints should be sent to Robert J. Sbordone, Department of Psychiatry/Biobehavioral Sciences, Neuropsychiatric Institute, UCLA Medical School Center for the Health Sciences, University of California at Los Angeles, Los Angeles, California 90024. affects the behavior of the dominant animal in the colony. The present study compares the aggressive behavior of rats in an all-male colony with the behavior elicited by footshock.

\section{METHOD}

\section{Subjects}

Thirty-two experimentally naive male Sprague-Dawley rats, between 90 and 100 days old at the start of the experiment, were obtained from the Simonsen Breeding Laboratory, Gilroy, California, and served as the subjects for this experiment. Regardless of the type of housing, food and water were available at all times.

\section{Apparatus}

The rat colony consisted of a galvanized steel mesh chamber ( $1 \mathrm{~m}$ in width by $2.0 \mathrm{~m}$ in length by $1.5 \mathrm{~m}$ in height) that was divided into two tiers of equal size to form upper and lower compartments. An inclined ramp connected the compartments and permitted the animals to move from one compartment to another.

The experimental chamber used to test the animals with shock consisted of a cylinder with inside dimensions of $30 \mathrm{~cm}$ in diameter by $30 \mathrm{~cm}$ in height. The entire chamber was constructed of clear Plexiglas, which allowed an unobstructed view of its interior. The grid floor of this chamber consisted of $.634-\mathrm{cm}$ stainless steel rods, spaced $1.3 \mathrm{~cm}$ apart (center to center). Electric shock was delivered through the floor grids, operating through a Davis Model 255 grid scrambler. The duration of shock and the interval between shocks were controlled by two Davis Model D 501 time-interval generators. The intensity of the shock current was continuously monitored throughout each experimental session.

\section{Procedure}

Each rat was initially housed in an individual cage for 60 days prior to the start of the experiment. At this time, their tails were colored with distinctive dyes to permit individual recognition, and they were placed in the rat colony for 7 days. After the rat had spent $48 \mathrm{~h}$ in the colony, each instance of aggressive behavior was recorded by an experienced observer for a total of $36 \mathrm{~h}$ during the remaining 5 days (one-third of these observations were made in the morning, afternoon, and evening, respectively). The following criteria were used to identify aggressive behavior: aggressive grooming (a rat mouths or licks the fur of another rat following an attack during which the 
latter is knocked to the ground and held securely with the forepaws), shoving (a rat delivers a forcible push or shove to another rat with one or both forepaws), boxing (a rat strikes another rat with rapid boxing-like movement, using its forepaws), bite attempt (a rat lunges forward in an attempt to bite another rat), and biting (a rat bites another rat). On the eighth day, 16 rats were selected at random and were removed from the colony and paired together on the basis of similar body weight; they were then tested one pair at a time with footshock. Each pair of rats received 100 shocks at $2.0-\mathrm{mA}$ intensity of $1.5 \mathrm{sec}$ duration every $30 \mathrm{sec}$. Each testing session lasted approximately $52 \mathrm{~min}$. The criteria used to identify and record aggressive behavior in this situation was exactly the same as in the rat colony.

\section{RESULTS}

Table 1 presents a comparison of the aggressive behavior of the rats observed in the colony and in the shock chamber. It can be seen that behaviors such as aggressive grooming, biting attempts, and biting of an opponent were observed in the rat colony, but were not observed when these animals were tested with footshock. While boxing and shoving behaviors were observed in both situations, some of the components of these behaviors that were observed in the colony were not observed during shock. For example, rats in the colony were observed to bob and weave when they boxed; this was not observed at any time in the shock situation. Shoving, when it occurred in the colony, consisted of lunging toward an opponent that frequently knocked the latter to the ground; this was not observed in the shock chamber, although there was sufficient room in the chamber for this to occur. Instead, the shoving response to footshock consisted of reflexive pushing movements with the forepaws.

\section{DISCUSSION}

Since many of the aggressive behaviors observed in colony were not seen with shock and those that were observed in the footshock situation were missing several behavioral components, behaviors that have been termed as "aggressive" or "defensive" in response to footshock may be what ethologists have termed as "displacement" activity. Armstrong (1950) has used this term to describe behaviors that are incomplete and eccentric and that occur when there is competition between two incompatible behavioral tendencies present in a given situation. In the case of the shock-elicited aggression situation, the delivery of footshock to a pair of animals in a small inescapable enclosure elicits incompatible flight and threat responses. A close examination of the shock-elicited aggression literature in rats reveals that the likelihood that "aggressive" behavior to footshock will occur appears to be a function of the degree to which certain variables present in this situation either increase or decrease the conflict. For example, shock-elicited aggression is virtually absent when a pair of rats is shocked in a large chamber that increases the likelihood of responses such as running and decreases the likelihood of threat responses (Ulrich \& Azrin, 1962). Intense shock that tends to markedly increase flight behavior virtually abolishes aggressive behavior (Ulrich, 1966). When one member of the pair is anesthetized or immobile, aggressive behavior is absent (Carder \& Sbordone, 1975; Knutson, 1971; Powell et al., 1969). When one member of the pair receives partial
Table 1

Comparison of the Aggressive Behavior of Rats in a Colony and During Footshock

\begin{tabular}{|c|c|c|c|c|}
\hline \multirow{2}{*}{$\begin{array}{l}\text { Aggressive } \\
\text { Behavior }\end{array}$} & \multicolumn{2}{|c|}{ Colony } & \multicolumn{2}{|c|}{ Shock } \\
\hline & Total & $\mathrm{p}$ & Total & $\mathrm{p}$ \\
\hline Shoving & 66 & .115 & 47 & .153 \\
\hline Boxing & 314 & .546 & 260 & .847 \\
\hline Aggressive Grooming & 162 & .282 & 0 & .000 \\
\hline Attempts to Bite Opponent & 16 & .028 & 0 & .000 \\
\hline Biting an Opponent & 17 & .029 & 0 & .000 \\
\hline Total & 575 & & 307 & \\
\hline
\end{tabular}

reinforcement for escaping from the chamber, aggressive behavior is abolished (Sbordone, Note 2). Exposing individual rats to inescapable shock that elicits running and jumping behavior abolished aggressive behavior when the rats were later paired and given footshock (Powell \& Creer, 1969; Tondat, 1974). Fighting is rarely, if ever, observed during the intershock interval and rarely exceeds shock termination (Sbordone \& Carder, 1974; Ulrich, 1966; Ulrich \& Azrin, 1962). Aggressive behavior is virtually absent when the footshock is delivered when the animals are facing away from each other, but is almost certain when they are facing each other (Sbordone, Garcia, \& Carder, 1977). When only one member of the pair receives shock, aggressive behavior is virtually absent (Ulrich, 1966).

The data in the present study are consistent with the findings of Turner, Boice, and Powers (1973), who reported that ground squirrels display upright boxing postures in response to footshock, whereas this behavior has never been observed in this species in natural settings. They also noted that many of the components of threat behavior (such as tooth chattering, growling, tail held to one side, and piloerection) were conspicuously absent, whereas the particular threat posture observed in response to footshock situation (i.e., back arched and head held low) has never been observed in natural settings. Thus, investigators may be observing displacement activity, rather than defensive or aggressive behavior, when footshock is delivered.

\section{REFERENCE NOTES}

1. Powell, D. C. Shock-elicited aggression: An animal model of defensive behavior. Paper presented at the annual meeting of the Eastern Psychological Association, April 1974.

2. Sbordone, R. J. A rat model of violent attack behavior. Dissertation Abstracts International, 1976, 37, 213. .

\section{REFERENCES}

Armstrong, E. A. The nature of displacement activities. Symposium of the Society of Experimental Biology, 1950, 4, 361-384.

Blanchard, R. J., \& Blanchard, D. C. Aggressive behavior in the rat. Behavioral Biology, 1977, 21, 197-224.

Blanchard, R. J., Blanchard, D. C., \& Takahashi, L. K. Reflexive fighting in the albino rat: Aggressive or defensive behavior? Aggressive Behavior, 1977, 3, 145-156.

CARDER, B., \& SBORDone, R. J. Mescaline-treated rats attack immobile targets. Pharmacology, Biochemistry and Behavior, 1975, 3, 923-925.

KNutson, J. F. The effects of shocking one member of a pair of rats. Psychonomic Science, 1971, 22, 265-267.

MiczeK, K. A. Intraspecies aggression in rats: Effects of d-amphetamine and chlordiazepoxide. Psychopharmacologia, 1974, 39, 275-301. 
MOYER, K. E. The psychobiology of aggression. New York: Harper \& Row, 1976.

Powell, D. A., \& CREer, T. L. Interaction of developmental and environmental variables in shock-elicited aggression. Journal of Comparative and Physiological Psychology, 1969, 69, 219-225.

Powell, D. A., Frances, J., Braman, M. J., \& Schneiderman, N. Frequency of attack in shock-elicited aggression as a function of the performance of individual rats. Journal of the Experimental Analysis of Behavior, 1969, 12, 817.823.

Sbordone, R. J., \& CARDER, B. Mescaline and shock-induced aggression in rats. Pharmacology, Biochemistry and Behavior, 1974, 2, 777-782.

Sbordone, R. J., Garcia, J., \& Carder, B. Shock-elicited aggression: Its displacement by a passive social orientation avoidance response. Bulletin of the Psychonomic Society, 1977, 9, 272-274.
Tondat, L. M. Is the effect of preshock treatment on shockelicited aggression independent of situational stimuli? Psychological Record, 1974, 24, 409-417.

Turner, J. L., BoIce, R., \& Powers, P. C. Behavioral components of shock-induced aggression in ground squirrels (Citellus Tridecemlineatus). Animal Learning \& Behavior, 1973, 1, 254-262.

UlRICH, R. E. Pain as a cause of aggression. American Zoologist, 1966, 6, 643-662.

Ulrich, R. E., \& AzRIN, N. H. Reflexive fighting in response to aversive stimulation. Journal of the Experimental Analysis of Behavior, 1962, 5, 511-520.

(Received for publication August 2, 1978.) 